\title{
Frequency and temperature dependent selection at the alcohol dehydrogenase-1 locus of Drosophila buzzatii
}

P. H. Cooke*, J. S. F. Barker and P. D. East $\dagger$

\author{
Department of Animal Science, University of New
} England, Armidale, N.S.W. 2351, Australia.

Genotype frequencies at the alcohol dehydrogenase-1 (Adh-1) locus of $D$. buzzatii were analysed for deviations from Hardy-Weinberg equilibria in the progeny of laboratory populations established at five initial $A d h-1^{b}$ allele frequencies and kept at either $18^{\circ} \mathrm{C}, 25^{\circ} \mathrm{C}$ or $30^{\circ} \mathrm{C}$. At $25^{\circ} \mathrm{C}$, no observed genotype frequencies were significantly different from Hardy-Weinberg expectations. Observed frequencies of heterozygotes were generally less than expected for populations at $18^{\circ} \mathrm{C}$ and $30^{\circ} \mathrm{C}$. Fitness differences among genotypes were greater in males than in females, with $A d h-1^{b}$ homozygotes having highest fitness at $18^{\circ} \mathrm{C}$ and $A d h-1^{c}$ homozygotes having highest fitness at $30^{\circ} \mathrm{C}$. The results are discussed in relation to previous field and laboratory studies on $D$. buzzatii and to the Adh polymorphism of D. melanogaster.

\section{INTRODUCTION}

Of the two Adh loci in Drosophila buzzatii, Adh-2 is essentially monomorphic, while $A d h-1$ is highly polymorphic, with mean frequencies for 50 field populations averaging 55 per cent $A d h-1^{b}$ and 45 per cent $A d h-1^{c}$ (Barker and Mulley, 1976). Evidence for natural selection affecting allele frequencies at the $A d h-1$ locus was found by Barker and East (1980); following artificial perturbation of a natural population, a return to pre-perturbation $A d h-1$ allele frequencies occurred within a year.

The question of selection on the $A d h$ polymorphism in $D$. melanogaster due to environmental factors such as alcohol or temperature has not been resolved (Oakeshott et al., 1985;Oakeshott et al., 1984; Oakeshott et al., 1982b; van Delden, 1982). The exploration of $A d h-1$ variation in $D$. buzzatii may provide new insight into mechanisms of selection on an $A d h$ polymorphism since this species has a better defined ecology and differs in the organisation of the $A d h$ gene. $D$. melanogaster is cosmopolitan and possesses one Adh locus. On the other hand, D. buzzatii is niche

* Present address: Department of Population Biology, Research School of Biological Sciences, Australian National University, Canberra, A.C.T. 2601, Australia.

$\dagger$ Present address: Department of Genetics, University of California, Berkeley, California, U.S.A. 94720. specific, feeding and breeding exclusively in rots of cactus species (Barker and Mulley, 1976), and has two closely linked $A d h$ loci, thought to result from a gene duplication (Oakeshott et al., 1982a). If, despite these differences, allele frequency changes are observed as a result of exposure of $D$. buzzatii to environmental stresses in the laboratory, which are similar to those found for $D$. melanogaster, then the argument for differential selection acting on Adh alleles is, in general, strengthened.

Several field and laboratory studies have suggested that temperature may be a selective agent on $A d h-1$ allele frequencies in D. buzzatii (Mulley et al., 1979; Watt, 1981; Barker et al., 1986). This study was designed to determine the effects of rearing temperature on genotype frequencies in laboratory populations of $D$. buzzatii over one generation. In addition, these populations were initiated at different $A d h-1^{b}$ allele frequencies to test for possible frequency dependent selection (Kojima and Tobari, 1969; Yoshimaru and Mukai, 1979).

\section{MATERIALS AND METHODS}

Stocks were reared on a medium comprising 19 per cent blended Opuntia stricta cactus, 6 per cent yeast, 4 per cent sucrose, 1 per cent nipagin, 
$1 \times 10^{-4}$ per cent propionic acid, $2 \times 10^{-5}$ per cent streptomycin and $3 \times 10^{-4}$ per cent terramycin $(\mathrm{w} / \mathrm{v})$. Forty $\mathrm{ml}$ of medium were used to culture flies in bottles of $140 \mathrm{ml}$ total volume.

Female D. buzzatii were captured at Hemmant, Queensland (locality 31 of Barker and Mulley, 1976) and their progeny cultured as single pair full sib matings for five generations. Adh-1 genotype was monitored by electrophoresis at each generation and 61 independently derived homozygous $A d h-1^{b}$ and 19 independently derived homozygous $A d h-1^{c}$ isofemale lines were founded. Two homozygous stock populations, one from the 61 $A d h-1^{b}$ lines and the other from the $19 A d h-1^{c}$ lines, were set up and maintained at 200 pairs of parents ( 10 bottles) for a further seven generations prior to the experiment.

A factorial experimental design was used to determine the effects on $A d h-1$ genotype frequency after a single generation of two treatments, viz. initial $A d h-1$ allele frequency (5 levels), and temperature ( 3 levels). To achieve the five frequency levels, six-day old virgin flies from the homozygous stock populations were mass mated for 24 hours at $25^{\circ} \mathrm{C}$, in one of four crosses, viz. $q^{b b} \times \delta^{b b}, q^{b b} \times$ $\delta^{c c}, o^{c c} \times \delta^{b b}$ and $\wp^{c c} \times \delta^{c c}$. Females from the four cross types were then combined in five classes of Hardy-Weinberg equilibrium proportions to give expected allele frequencies in the progeny for the $A d h-1^{b}$ allele of $0 \cdot 9,0 \cdot 7,0 \cdot 5,0 \cdot 3$ and $0 \cdot 1$. The total number of females in any one bottle was 100 .

Twelve bottles were prepared for each of the five $A d h-1^{b}$ frequency classes. Four bottles per frequency class were then set at one of three temperatures, $18^{\circ} \mathrm{C}, 25^{\circ} \mathrm{C}$ or $30^{\circ} \mathrm{C}$. The experiment was repeated one week later to give an additional four replicates for each treatment.

Horizontal starch gel electrophoresis using Buffer III of Shaw and Prasad (1970), modified with the addition of $1 \mathrm{mg} / \mathrm{ml} \mathrm{MgCl}_{2}$ to the gel buffer, was used to score individual progeny. Gels were stained with $4.5 \mathrm{ml}$ 2-propanol, $50 \mathrm{mg} \beta$ NAD, $30 \mathrm{mg}$ MTT, and $3 \mathrm{mg}$ PMS in $100 \mathrm{ml}$ Tris$\mathrm{HC} 1 \mathrm{pH} 8.5$, and incubated at $37^{\circ} \mathrm{C}$ for 30 to 60 minutes (Barker et al., 1986). A sample of 50 oneday old adults of each sex from each bottle (taken proportionately from the daily emergence distribution) was assayed for $A d h-1$ genotype, although some bottles produced fewer flies than required, and for the $25^{\circ} \mathrm{C}, 0.1$ initial frequency treatment, some additional flies were assayed. At $30^{\circ} \mathrm{C}$, bacterial contamination caused the loss of one replicate in each of the $0 \cdot 1,0.3$ and 0.5 treatments, and two replicates in the 0.7 treatment. One replicate of the $18^{\circ} \mathrm{C}, 0.9$ treatment was deleted from the data set because of extremely aberrant observed numbers ( $50 b b, 50 b c)$, presumably due to an error at setting up this bottle.

\section{RESULTS}

Two major effects on $A d h-1$ genotype frequencies were found. Firstly, significant deviations from Hardy-Weinberg expected genotype numbers were observed at both $18^{\circ} \mathrm{C}$ and $30^{\circ} \mathrm{C}$, but not at $25^{\circ} \mathrm{C}$ (table 1). These deviations took the form of heterozygote deficiencies for all five of the initial $A d h-1^{b}$ allele frequency classes at $18^{\circ} \mathrm{C}$, and for four at $30^{\circ} \mathrm{C}$. The exception at $30^{\circ} \mathrm{C}$ was the 0.9 initial frequency class where a significant excess was recorded. In a graphic description of the table 1 data (fig. 1) a trend for genotype frequency dependent selection can be seen at $30^{\circ} \mathrm{C}$, where the fitness of the $A d h-1^{b}$ homozygotes increases as $A d h-1^{b}$ frequency decreases. The observed heterozygote deficiencies in the pooled data for the $18^{\circ} \mathrm{C}$ and $30^{\circ} \mathrm{C}$ treatments (excluding $30^{\circ} \mathrm{C}, 0.9$ ) were not aue to a Wahlund efiect, since 48 of the 66 replicate bottles in these nine treatments had an observed deficiency of heterozygotes (29 of these significant), 16 an observed excess ( 5 significant), and two no difference.

Secondly, genotype fitnesses varied with temperature and differences were larger in males than in females (table 2). $A d h-1^{b}$ homozygotes had highest fitness at $18^{\circ} \mathrm{C}$, while $A d h-1^{c}$ were highest at $30^{\circ} \mathrm{C}$.

\section{DISCUSSION}

Temperature had a large effect on $A d h-1$ heterozygosity, with heterozygote numbers reduced at both low $\left(18^{\circ} \mathrm{C}\right)$ and high $\left(30^{\circ} \mathrm{C}\right)$ temperatures, but not at the intermediate temperature $\left(25^{\circ} \mathrm{C}\right)$.

As both high and low temperatures gave similar results, it is difficult to relate this study to the field results (Barker et al., 1986) where heterozygote frequency varied seasonally (with respect to Hardy-Weinberg equilibrium), rising in summer and falling in winter. This discrepancy may be because the range of temperatures tested in this study is much narrower than those which $D$. buzzatti experience in the wild, or because of the homogeneity of the laboratory environment in contrast to diurnal temperature variation in the field, or because effects on larvae are compensated by different effects at other life cycle stages. 
Table 1 Observed and expected numbers and their $\chi^{2}$ values for each $A d h$ - 1 genotype for each treatment combination of temperature and initial gene frequency. Expected numbers were calculated using initial frequency values of $p$ and $q$ from the four cross types giving rise to the progeny

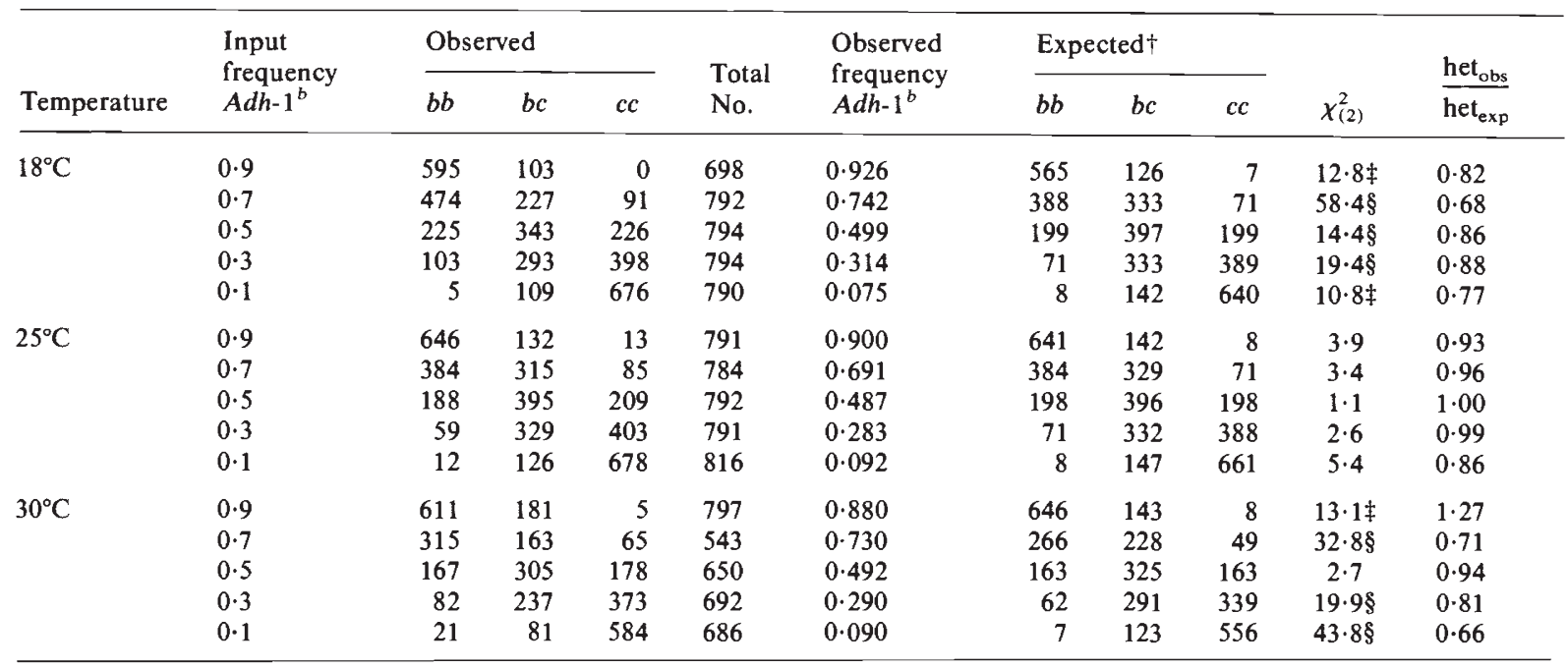

$\dagger$ Based on input frequency.

$\ddagger P<0.01$.

$\S P<0.001$.

Although decreased heterozygote fitness is an unusual result it is not without precedent in similar experiments. A reduction in heterozygote frequency related to temperature has been observed for the $\alpha-G p d h$ locus in $D$. melanogaster, where genotypes emerged in Hardy-Weinberg equilibrium at $16^{\circ} \mathrm{C}$ and $20^{\circ} \mathrm{C}$, but at $28^{\circ} \mathrm{C}$ a significant decrease in heterozygote fitness was observed (McKechnie et al., 1981).

Clinal variation for the $A d h$ polymorphism in $D$. melanogaster has been well documented (Oakeshott et al., 1982b) and a study of D. buzzatii Adh-1 allele frequencies in eastern Australia showed significant spatial heterogeneity, with Adh- $1^{b}$ frequency decreasing with increasing distance from the coast and increasing latitude (Mulley et al., 1979). In a laboratory study of the effects of cold shock $\left(0^{\circ} \mathrm{C}\right.$ for 5 days $)$, a decrease in the frequency of $A d h-1^{b}$ was found among survivors (Watt, 1981). This decrease is consistent with the direction of the latitudinal variation, but appears to conflict with the present study, where a higher fitness was found for $A d h-1^{b}$ homozygotes at the lowest temperature $\left(18^{\circ} \mathrm{C}\right)$, rather than the highest $\left(30^{\circ} \mathrm{C}\right.$ ) (table 2$)$. However, the cold shock experiment of Watt (1981) tested adult survival only, i.e., a fitness component not involved in the present study. Here selection on $A d h-1$ genotype frequen-
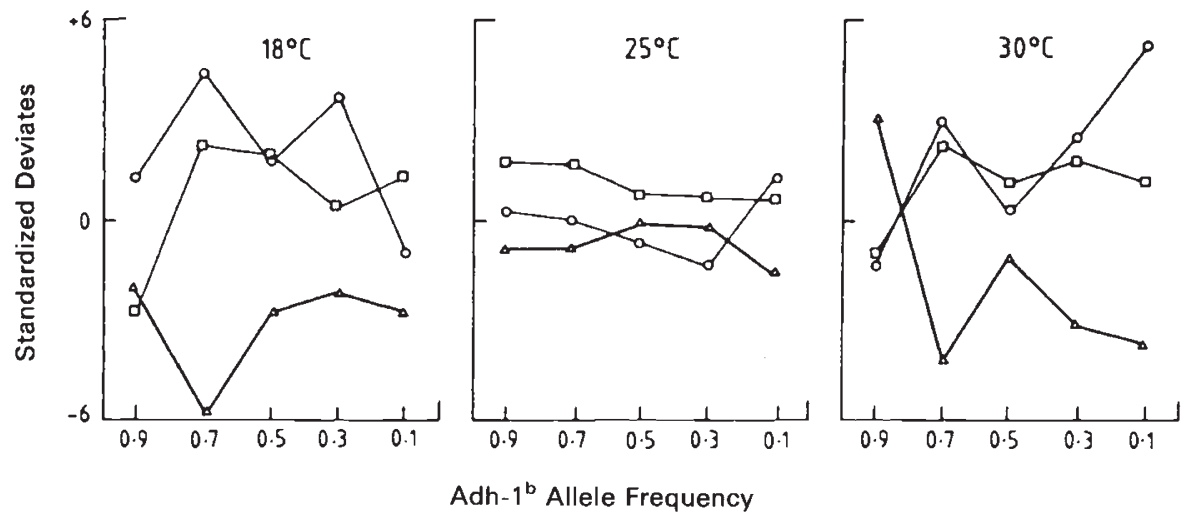

Adh $-1^{\text {b }}$ Allele Frequency

Figure 1 Standarised deviates (obs-exp/SQRTexp) for each temperature, initial $A d h-1^{b}$ frequency and genotype (from data in table 1). $\bigcirc A d h-1^{b b}, \triangle A d h-1^{b c}, \square A d h-1^{c c}$. 
Table 2 Standardised deviates (obs-exp/SQRTexp) and $\chi^{2}$ values for genotype by temperature for each sex

\begin{tabular}{|c|c|c|c|c|c|c|c|c|}
\hline \multicolumn{9}{|c|}{ Genotype } \\
\hline & \multicolumn{4}{|c|}{ Female } & \multicolumn{4}{|l|}{ Male } \\
\hline & $b b$ & $b c$ & $c c$ & $\chi_{(2)}^{2}$ & $b b$ & $b c$ & $c c$ & $\chi_{(2)}^{2}$ \\
\hline $18^{\circ} \mathrm{C}$ & $2 \cdot 7$ & $-4 \cdot 2$ & $1 \cdot 6$ & $27 \cdot 68 \S$ & $4 \cdot 2$ & $-5 \cdot 7$ & $1 \cdot 7$ & $52 \cdot 80 \S$ \\
\hline $25^{\circ} \mathrm{C}$ & $1 \cdot 1$ & $-2 \cdot 4$ & $1 \cdot 3$ & $8.45^{*}$ & $-1 \cdot 7$ & 0.5 & $1 \cdot 2$ & $4 \cdot 37$ \\
\hline $30^{\circ} \mathrm{C}$ & 0.8 & $-2 \cdot 3$ & $1 \cdot 5$ & $8.03^{*}$ & 1.4 & $-3 \cdot 8$ & $2 \cdot 4$ & $22 \cdot 25 \S$ \\
\hline
\end{tabular}

$* P<0.05$.

$\S P<0.001$.

cies could have occurred at one or many of the life stages of the test animals, including effects on fertility and oviposition behaviour of the parent females which oviposited in each treatment under test conditions. One stage at which selection might be expected is the larval stage, since $A d h-1$ activity peaks during that stage (Batterham et al., 1984). In any case, genotype differences for adult survival need not be in the same order as for other components of fitness.

Some controversy exists in the literature over genotype frequency dependent selection at the $A d h$ locus of $D$. melanogaster. One study (Kojima and Tobari, 1969) showed genotype frequency dependent selection to occur, with the genotype at lowest frequency having enhanced fitness. A later study (Yoshimaru and Mukai, 1979) found no effect. Weak evidence for genotype frequency dependent selection can be seen in $D$. buzzatii at $30^{\circ} \mathrm{C}$, where the fitness of the heterozygote decreases, and that of both homozygotes increases as $A d h-1^{b}$ frequency decreases (fig. 1). It is noteworthy that the parental generation was made up of homozygotes only. Hence the point made by Prout (1965), that fitnesses estimated from a comparison of progeny with parental genotype frequencies can show spurious frequency dependent selection, is not relevant here.

As in all other experiments of this type, the possibility that another locus closely linked to $A d h-1$ is the primary site for selection cannot be discounted. However, the background genome of test stocks was randomised during the breeding program such that in the absence of epistatic selection only closely linked genes would be likely to remain in disequilibrium with $A d h-1$. Studies of D. mojavensis, a member of the mulleri sub-group to which $D$. buzzatii belongs, have shown $A d h$ to be located on Chromosome III (Zouros, 1976) and preliminary experiments indicate that $D$. buzzatii $A d h-1$ is on the same chromosome. Chromosome III of $D$. buzzatii is not known to have any inversions (Knibb, personal communication) so linkage disequilibria due to inversions will not be occurring.

This experiment has shown that temperature is a component of the environment affecting $A d h-1$ genotype frequencies in laboratory populations of D. buzzatii, so $A d h-1$ frequencies may be influenced by environmental temperature in nature. However, the lack of agreement between this study and field observations in terms of the direction of the effect suggests that any selection on the $A d h-1$ locus due to temperature in wild populations is more complex than that indicated here. Such complexity is evidenced by fitness differences between the sexes at $18^{\circ} \mathrm{C}$ and $30^{\circ} \mathrm{C}$ (table 2), where effects on genotype frequencies were found to be greater for males than females, suggesting differential selection between the sexes. Differences in $A d h-1$ allele frequency have been associated with other variables such as the age of the cactus cladode rot, its $p \mathrm{H}$ and the number of flies emerging from it (Barker et al., 1986), indicating that the microenvironment may be just as important in maintaining the polymorphism as the macro-environment. Two things are clear: observed heterozygote excesses occur for Adh-1 in the wild (Barker et al., 1986) and heterozygosity can be manipulated by factors such as temperature and initial gene frequency in the homogeneous laboratory environment.

Acknowledgements This work has been supported by a grant from the Australian Research Grants Committee to J. S. F. Barker. Critical appraisal of the manuscript by John Oakeshott, Stephen McKechnie and Rollin Richmond was of great benefit, and we thank an anonymous referee for the comment relating to Prout (1965). Many thanks to M. M. Green, W. T. Starmer, A. Y. Game, W. R. Knibb, P. R. Anderson, J. A. Benzie and D. M. Rowell for valuable discussions.

\section{REFERENCES}

BARKER, J. S. F. AND EAST, P. D. 1980. Evidence for selection following perturbation of allozyme frequencies in a natural population of Drosophila. Nature, 284, 166-168. 
BARKER, J. S. F., EAST, P. D. AND WEIR, B. S. 1986. Temporal and microgeographic variation in allozyme frequencies in a natural population of Drosophila buzzatii. Genetics, 112, 577-611.

BARKER, J. S. F. AND MULLEY, J. C. 1976. Isozyme variation in natural populations of Drosophila buzzatii. Evolution, 30, 213-233.

BATTERHAM, P., CHAMBERS, G. K., STARMER, W. T. AND SULLIVAN, D. T. 1984. Origin and expression of an alcohol dehydrogenase gene duplication in the genus Drosophila. Evolution, 38, 644-657.

KOJIMA, K. AND TOBARI, Y. N. 1969. The pattern of viability changes associated with genotype frequency at the alcohol dehydrogenase locus in a population of Drosophila melanogaster. Genetics, 61, 201-209.

MCKECHNIE, S. W., KOHANE, M. AND PHILLIPS, S. C. 1981. A search for interacting polymorphic enzyme loci in Drosophila melanogaster. In Gibson, J. B. and Oakeshott, J. G. (eds.), Genetic Studies of Drosophila Populations, Australian National University, Canberra, pp. 121-138.

MULLEY, J. C., JAMES, J. W. AND BARKER, J.S. F. 1979. Allozyme genotype-environment relationships in natural populations of Drosophila buzzatii. Biochem. genet., 17, 105-126.

OAKESHOTT, J. G., CHAMBERS, G. K., EAST, P. D., GIBSON, J. B. AND BARKER, J. S. F. 1982a. Evidence for a genetic duplication involving alcohol dehydrogenase genes in Drosophila buzzatii and related species. Aust. J. Biol. Sci., $35,73-84$.

OAKESHOTT, J. G., GIBSON, J. B., ANDERSON, P. R., KNIBB, W. R., ANDERSON, D. G. AND CHAMBERS, G. K. 1982 b.
Alcohol dehydrogenase and glycerol-3-phosphate dehydrogenase clines in Drosophila melanogaster on different continents. Evolution, 36, 86-96.

OAKESHOTT, J. G., GIBSON, J. B. AND WILSON, S. R. 1984. Selective effects of the genetic background and ethanol on the alcohol dehydrogenase polymorphism in Drosophila melanogaster. Heredity, 53, 51-67.

OAKESHOTT, J. G., WILSON, S. R. AND PARNELL, P. 1985. Selective effects of temperature on some enzyme polymorphisms in laboratory populations of Drosophila melanogaster. Heredity, 55, 69-82.

PROUT, T. 1965. The estimation of fitnesses from genotypic frequencies. Evolution, 19, 546-551.

SHAW, C. R. AND PRASAD, R. 1970. Starch gel electrophoresis of enzymes-a compilation of recipes. Biochem. genet., 4, 297-320.

VAN DELDEN, w. 1982. The alcohol dehydrogenase polymorphism in Drosophila melanogaster. Evol. Biol., 15, 187222.

WATT, A. W. 1981. The genetics of temperature tolerance in Drosophila buzzatii. In Gibson, J. B.. and Oakeshott, J. G. (eds.), Genetic Studies of Drosophila Populations. Australian National University, Canberra, pp. 139-146.

YOSHIMARU, H. AND MUKAI, T. 1979. Lack of experimental evidence for frequency dependent selection at the alcohol dehydrogenase locus in Drosophila melanogaster. Proc. Natl. Acad. Sci. USA 76, 876-878.

zOUROS, E. 1976. The distribution of enzyme and inversion polymorphism over the genome of Drosophila: Evidence against balancing selection. Genetics, 83, 169-179. 